Bulletin d'Histoire Contemporaine de l'Espagne

$51 \mid 2017$

Les forces politiques durant la Seconde République espagnole

\title{
Un momento decisivo: la estrategia de la CEDA ante las elecciones de 1936
}

Un moment décisif: la stratégie de la CEDA face aux élections de 1936

A decisive moment: the strategy of CEDA when the elections of 1936

\section{Manuel Álvarez Tardío}

\section{OpenEdition \\ Journals}

Edición electrónica

URL: http://journals.openedition.org/bhce/660

DOI: $10.4000 /$ bhce. 660

ISSN: 1968-3723

Editor

Presses Universitaires de Provence

Edición impresa

Fecha de publicación: 1 junio 2017

Paginación: 53-68

ISSN: 0987-4135

Referencia electrónica

Manuel Álvarez Tardío, « Un momento decisivo: la estrategia de la CEDA ante las elecciones de 1936 », Bulletin d'Histoire Contemporaine de l'Espagne [En línea], 51 | 2017, Publicado el 09 octubre 2018,

consultado el 30 abril 2019. URL : http://journals.openedition.org/bhce/660 ; DOI : 10.4000/bhce.660 


\title{
Un momento decisivo: la estrategia de la CEDA ante las elecciones de 1936*
}

\author{
Manuel ÁLVAREZ TARDío
}

Universidad Rey Juan Carlos

$\mathrm{E}$

n un trabajo de síntesis publicado a comienzos de los años noventa, Martin Blinkhorn

relataba los aspectos fundamentales de la evolución de los conservadores en la España del primer tercio del siglo XX. Llegado el turno de la Segunda República, el autor señalaba con acierto lo importante que era enfatizar el hecho de que la derecha monárquica alfonsina no fue, durante los treinta, «un verdadero partido político» sino un «grupo» de personas bien situadas en la escala social que nunca llegó a ser un movimiento de masas. Renovación Española, como señalaría un carlista, fue «un alto mando sin ejército». Quizá por eso, por su escasa capacidad de seducir y movilizar a las masas, los alfonsinos se centraron en una estrategia propia de un grupo de presión consciente de su debilidad, bien tratando de influir sobre las elites políticas o bien dedicándose a la conspiración y la «desestabilización» de la República.

Para Blinkhorn, el «fracaso» de los monárquicos alfonsinos era «atribuible directamente» al «éxito» de eso que suele llamarse «accidentalismo». Este principio habría sido propuesto fundamentalmente por el sector de los Propagandistas y El Debate y aprovechado, con éxito, por la organización de Acción Popular. Estos, sobre todo después del fracaso de la Sanjurjada en agosto de 1932, impulsaron una línea de acción conservadora basada en una combinación calculada de respeto a la legalidad vigente y denuncia de algunos aspectos de la legislación y el marco constitucional. Así, en marzo de 1933, con la fundación de la CEDA y la separación de caminos entre cedistas y monárquicos de Renovación Española, surgió una derecha nueva, de hecho el «partido político más grande» nunca visto antes en España, al menos por número de afiliados ${ }^{1}$.

De acuerdo con Blinkhorn, bajo el liderazgo de Gil Robles, la CEDA siguió una estrategia orientada a lograr el poder dentro del régimen para luego transformarlo en un estado corporativo, fijándose no tanto en el caso alemán como en el modelo de los social-cristianos austriacos. Pero Blinkhorn, a diferencia de otras interpretaciones algo frívolas sobre la naturaleza de la CEDA, puntualizaba con acierto que la base de la derecha católica era una inspiración tradicionalista que les llevaba a desconfiar por encima de todo del Estado moderno, fuera éste inspirado por principios liberales, socialistas o fascistas. Anhelaban un Estado vinculado a una visión de una armonía social premoderna.

* Este trabajo se inserta en un proyecto del ministerio español de Economía con referencia: HAR2012-31520.

1 M. BLInKHoRn, «Conservatism, Traditionalism and fascism in Spain, 1898-1937», en Blinkhorn, M (ed.), Fascists and Conservatives. The radical right and the establishment in twentieth-century Europe, Londres, Routledge, 2005, p. 127-131. 
No todos los que han escrito sobre la CEDA compartirían un análisis como éste, en el que el acento está puesto en la comprensión de los aspectos que diferenciaban a la CEDA de otras derechas radicales y/o autoritarias, recordando que, dadas sus bases ideológicas, la mayoría de los cedistas estaban poco predispuestos a abanderar opciones fascistas o fascistizantes. Es evidente que esta forma de analizar a los cedistas no encaja con la de todos aquellos que han asumido, como principio indiscutible que no necesita ser refutado, que la CEDA era sólo una táctica de los conservadores autoritarios para destruir la República y que su verdadero propósito se revelaba en las tramas conspirativas y contrarrevolucionarias que buscaban dar el golpe de gracia a la democracia republicana e imponer una vía española hacia el corporativismo fascista ${ }^{2}$.

La historia del nacimiento de la CEDA y de los rasgos más sobresalientes de su evolución a lo largo del período republicano es bien conocida. Sin embargo, durante décadas las consideraciones de fondo sobre su papel y su relación con el régimen republicano no han estado exentas de polémica. No es que haya habido un debate profuso, basado en fuentes primarias. Al contrario, ha predominado un discurso ideológico en virtud del cual la CEDA actuó como un caballo de Troya cuyo objetivo era destruir la democracia republicana. En ese sentido, lejos de toda discusión desapasionada y argumentada sobre el papel de la derecha católica, a menudo se ha desestimado y desacreditado cualquier planteamiento que supusiera cuestionar ese modelo explicativo.

De este modo, durante mucho tiempo el análisis de la CEDA ha estado sometido a la tensión provocada por la idea preconcebida de que aquella fue una opción táctica legalista, pero con fines similares a los de los monárquicos autoritarios. A esto ha contribuido, sin duda, la constante referencia a lo que por entonces estaba ocurriendo en la República de Weimar, o al mismo caso austriaco, para certificar así ese peligro de utilización fraudulenta de los mecanismos democráticos con el objetivo final de destruir la democracia. Por otro lado, la ambivalencia del discurso de muchos cedistas, el radicalismo verbal en algunos mítines y la famosa apelación al «Estado nuevo» han fortalecido la imagen de una CEDA no ya antirrepublicana o corporativa, sino autoritaria e incluso parafascista. A eso se ha sumado siempre la referencia a los dislates de algunos sectores de las juventudes cedistas, especialmente en el duro contexto de finales de 1935, tras la negativa de Alcalá Zamora a encargar la formación de gobierno a la CEDA, aspecto éste que algunos autores han elevado a la categoría de principio general ${ }^{3}$.

La CEDA no aceptó plenamente la Constitución republicana porque consideró que lesionaba los derechos de los católicos y había sido diseñada para poner el Estado en manos de las izquierdas, al servicio de $s u$ revolución. Sabemos que, desde un punto de vista doctrinal, muchos cedistas se identificaban con una visión contraria a la modernidad liberal y culpaban al constitucionalismo liberal y a la democracia representativa del desorden social y el avance de la lucha de clases. Pero también sabemos que rechazaron una y otra vez la -violencia- salvo la que consideraban defensiva, es decir, si eran agredidos previamente y compitieron en las urnas con un grado de lealtad a las normas que no alcanzaron otros

2 El trabajo de referencia ha sido el J.R. Montero, La CEDA. El catolicismo social y politico en la Segunda República, Madrid, Ediciones de la Revista de Trabajo, 1977.

3 Un ejemplo reciente de cómo forzar una interpretación de la CEDA a la luz de ciertos aspectos de las juventudes de AP, en S. Lowe, Catholicism, War and the Foundation of Francoism. The Juventud de Acción Popular in Spain, 1931-1939, Brighton, Sussex Academic Press, 2010. 
representantes políticos que, paradójicamente, habían sido parte de la coalición fundacional de la democracia republicana ${ }^{4}$.

Uno de los contextos menos conocidos y seguramente más decisivos para comprender en profundidad la naturaleza de la CEDA y su difícil papel en la consolidación (o la modificación) de la democracia republicana, es el del final de la segunda legislatura, a partir del momento en que se hizo evidente la descomposición del Partido Radical y el presidente de la República decidió que Gil Robles no podía formar gobierno, alegando que la CEDA no se había presentado a las elecciones como un partido republicano ${ }^{5}$. El propósito de este artículo es arrojar luz sobre ese difícil contexto de los meses de diciembre de 1935 a febrero de 1936, especialmente en lo que se refiere al modo en que los cedistas plantearon su estrategia electoral. Hasta ahora se ha dado por supuesto que la CEDA afrontó esa campaña con un tono y unos propósitos si cabe más radicales que los expresados en 1933, por cuanto estaba enojada con la disolución de las Cortes y parecía cada vez más claro que el posibilismo había perdido todo sentido; y se ha asumido que si Gil Robles no pactó un bloque electoral con los monárquicos no fue porque no quisiera o no compartiera sus posiciones extremistas, sino porque se vio, más o menos, obligado por el pequeño sector moderado de su partido y por la necesidad de pactar en algunas provincias con los republicanos conservadores. Este artículo aporta datos que permiten matizar esas consideraciones.

La revolución de Octubre fue un shock para las derechas. Contribuyó a degradar la percepción sobre el adversario izquierdista y facilitó la explotación propagandística de la violencia revolucionaria. Por un momento se dejaron a un lado diferencias de calado entre los distintos grupos conservadores, compartiendo una imagen polarizada de la política española en la que la defensa de los principios formaba parte de una lucha existencial entre dos modelos de sociedad. Sin embargo, la hoja de ruta de la CEDA no cambió drásticamente. Uno de los nuevos ministros cedistas insistió en que ellos seguían «dispuestos a servir a la República» y creían que todos podían «resolver dentro de la legalidad sus aspiraciones». Gil Robles fue tajante al sostener que su grupo apoyaba al gobierno republicano de Lerroux e insistió en que la CEDA seguiría con la misma línea de conducta: «jamás, ni antes ni ahora, nos hemos colocado ni hemos de colocarnos en ningún terreno de violencia.» $\mathrm{Y}$ varias editoriales de El Debate ratificaron la línea legalista ${ }^{6}$.

En los últimos meses de 1934 la CEDA no puso en marcha una acción para aprovechar la situación posterior a Octubre y suspender la Constitución, como cabía haber esperado de un partido que quisiera acabar con la democracia republicana -y como, de hecho, pedía Calvo Sotelo- ${ }^{7}$. Si las conversaciones en los círculos de los monárquicos alfonsinos

4 No hago esta valoración a la ligera. Es fruto de mi exhaustivo estudio sobre la CEDA, la violencia y la intransigencia política, publicado en: «La CEDA y la democracia republicana», en F. DEL REY, ed., Palabras como puños. La intransigencia politica en la Segunda República española, Madrid, Tecnos, 2011, p. 397-409. También M. Álvarez TARDí, «Politics, Violence and Electoral Democracy in Spain: the case of the CEDA, 1933-1934», Bulletin for Spanish and Portuguese Historical Studies, $\mathrm{n}^{\circ} 35$ (1), 2011.

5 N. Alcala-Zamora, Memorias (Segundo texto de mis memorias), Barcelona, Planeta, 1977, p. 341-343.

6 J. Tusell, Historia de la Democracia Cristiana en España, Madrid, Sarpe, 1986, vol. I, p. 240-243. J.M. GL Robles, Discursos parlamentarios, Madrid, Taurus, 1971, p. 303. Y El Debate, 18-11, 15 y 18-12-1934.

7 Es muy significativa la polémica entre los firmantes del manifiesto fundacional del Bloque Nacional y Gil Robles a finales de 1934. En La Nación, 26-12-1934 y ABC, 27-12-1934. Cit. en S. GaLINDo 
y carlistas estaban presididas por una creciente ansiedad sobre la posibilidad de dar un golpe de gracia a la República aprovechando el contexto posrevolucionario, ese no fue el caso de Gil Robles ${ }^{8}$. Éste mantuvo su posición ya conocida, advirtiendo públicamente a los monárquicos que ellos aspiraban a una profunda «reforma de todo lo que se debe reformar», pero que sólo consideraban posible un camino, el «de las vías que la misma Constitución ha[bía] trazado». Y eso implicaba que llegaría «un momento en que, previo el acuerdo de los partidos o llevando a la opinión el resultado de nuestras discrepancias, pueda, dentro de los cauces legales, llegarse a lo que nosotros estimamos necesario» ${ }^{9}$.

No obstante, la verdadera encrucijada se le planteó a la CEDA, no en el post Octubre sino a finales de 1935, cuando el Presidente de la República se negó a encargar la formación del Gobierno al líder de la mayoría parlamentaria. A pesar de lo que aquél dijera para justificar su decisión, el problema no era la condición formalmente republicana o no de la CEDA, sino el hecho de que se estaba disolviendo el Partido Radical por mor de los escándalos de corrupción y Alcalá Zamora ya no podía controlar la formación de un gobierno parlamentario que no estuviera a merced de los cedistas. Además, tenía otro motivo para evitar un gobierno presidido por Gil Robles: justo en esos días estaba terminando su labor la comisión parlamentaria de reforma de la Constitución, que tenía ya casi listo un dictamen que recogía, entre otros aspectos, la modificación del polémico artículo $26^{10}$. Alcalá Zamora estaba a favor de la reforma constitucional, pero no de que fuera la CEDA la que capitalizara ese proceso. Así pues, dentro de su manera de entender la función presidencial, maniobró para que se formara un gobierno ajeno a la composición de la cámara y dispuesto a preparar el terreno para unas elecciones bien planificadas desde Gobernación.

Gil Robles consideró que la decisión del Presidente era contraria a las normas de un régimen parlamentario. Como le había pasado a Azaña en 1933, no estaba falto de razones, aunque el problema era también de diseño institucional de la Presidencia ${ }^{11}$. En un momento de profunda irritación tras una tensa conversación con Alcalá Zamora, su subsecretario en el departamento de Guerra, Fanjul, quiso convencer a Gil Robles de que era necesario impedir por la fuerza la maniobra presidencial. Éste respondió que no lideraría ese movimiento, aunque también dijo que apoyaría la acción que pudieran concertar los militares siempre que dieran «su palabra de honor» de que «esa acción se limitar[ía] rigurosamente a restablecer el normal funcionamiento de la mecánica constitucional y a permitir que la voluntad de la nación se expres[ara] con plena e ilimitada libertad $»^{12}$.

Herrero, Los partidos monárquicos bajo la Segunda República, Madrid, Rialp, 1956, p. 259. La evolución de las derechas autoritarias, en J. GL PECHARroman, Conservadores subversivos, La derecha autoritaria alfonsina, 1913-1936, Madrid, Eudema, 1994.

8 Son muy esclarecedoras las palabras que escribió Fal Conde a Sanjurjo a finales de 1934, refiriéndose a los cedistas no como aliados, sino todo lo contrario: «Es que vamos como los cangrejos o que los cangrejos del cedismo pueden más que los corceles de la reacción y nos hacen retroceder terreno. Y eso, que no dejamos de empujar, porque si paráramos, hace tiempo que nuestros antiguos aliados, nos habían [habrían] consolidado y echado raíces en la Niñita.» Carta fechada el 30-12-1934, en Archivo Privado Sanjurjo (s/c). Un estudio fundamental de la reacción de ese complejo mundo del conservadurismo autoritario después de octubre de 1934, en F. DEL REY, «Percepciones contrarrevolucionarias. Octubre de 1934 en el epistolario del general Sanjurjo» (en prensa).

9 DSC, n. 115, 5-11-1934, p. 4505.

$10 A B C, 5$ y $6-12-1935$.

11 M. Álvarez Tardío, «Ni República parlamentaria ni presidencialista», Revista de Estudios Politicos, $\mathrm{n}^{\circ} 123,2004$, p. 177-202.

12 J.M. Gll Robles, No fue posible la paz, Barcelona, Ariel, 2006, p. 365-367 y 381; Alcalá-Zamora, Memorias..., p. 344. Calvo Sotelo encargó a Juan A. Ansaldo que exigiera a Franco, Fanjul y Goded 
La maniobra quedó rápidamente descartada, entre otras razones porque no se trataba de una acción planificada de antemano y en la que la CEDA se fuera a involucrar con todas las consecuencias, como tampoco tenía un amplio respaldo en el alto mando militar. El mismo jefe del Estado Mayor, el general Franco, mostró su negativa a algo que implicaba una intervención militar en un problema que, a su juicio, debían resolver las autoridades civiles ${ }^{13}$. Así pues, la reacción pública de Gil Robles fue la de mantener su compromiso con la legalidad republicana. Criticó con dureza la resolución de la crisis de gobierno y acusó a sus antiguos aliados en el llamado «bloque gubernamental», por ejemplo Cambó, por su apoyo al Presidente. Pero, una vez más, se distanció de la posición de los extremistas monárquicos, alfonsinos y carlistas, negándose a dar por fracasado el posibilismo y reiterando, a preguntas de los periodistas sobre si la CEDA seguía en el «campo republicano», que: «Naturalmente. Otra cosa sería dar la razón a los que han supuesto en nosotros deslealtades de que somos incapaces. Dentro de la ley siempre. Y dentro del ámbito republicano también $\rangle^{14}$.

Finalmente, las Cortes fueron disueltas y se celebraron elecciones generales presididas por Portela Valladares, alguien a quien el propio Alcalá Zamora consideró «un táctico admirable» que fiaba «demasiado en la eficacia del poder» para ganar unas elecciones ${ }^{15}$.

El contexto para la celebración de unas generales en febrero de 1936 no podía ser menos propicio. El Debate explicó tras la constitución del nuevo gobierno que se había levantado «una muralla» para impedir que la CEDA pudiera hacer desde el gobierno lo que las urnas habían legitimado en noviembre de $1933^{16}$. Ciertamente, para éstos el giro inesperado de la situación política fue una noticia difícil de encajar, precisamente en el momento en que más cerca estaba la posibilidad de cumplir con su compromiso electoral y modificar la Constitución. Además, las heridas abiertas por lo de Octubre no estaban cicatrizadas; y ahora tocaba hacer frente en las urnas a unos partidos que habian prometido impedir a toda costa que la CEDA pudiera influir para cambiar el rumbo de la República del 31. En esas circunstancias, ¿cómo convencer a un votante conservador de que el posibilismo seguía teniendo sentido? ¿Cómo contrarrestar el discurso radical de un Calvo Sotelo que aseguraba abiertamente que la conciliación entre católicos y democracia republicana era inviable?

Los cedistas, además, estaban tan asustados como el resto de las derechas y el centro republicano, los progresistas, los de la Lliga y los Liberal Demócratas, por la vuelta al poder de quienes se habían salido de la ley en Octubre. Cabía esperar, por tanto, que el partido de Gil Robles se lanzara de inmediato a tejer una coalición electoral con la derecha monárquica para conseguir «todo el poder» en las elecciones y, ya sin la servidumbre de los radicales, cambiar la República y «aplastar» la revolución. Eso deseaban, desde luego, los extremistas monárquicos. La Nochebuena de 1935 el editorial de $A B C$ daba por hecha la «unión de derechas». Pero se trataba más de un acto de fe y de una forma de presión,

que se opusieran al "golpe de Estado» del Presidente de la República. En A. Bullón DE MendozA, José Calvo Sotelo, Barcelona, Ariel, 2004, p. 537.

13 La versión de Franco en una carta a Gil Robles, 4-2-1937. AHN, Causa General, Leg. 1513, exp 40.

14 Informaciones, 16-12-1935. Extracto de la entrevista publicado en $A B C, 17-12-1935$, p. 25.

15 N. Alcalá-Zamora, Asalto a la República. Enero-abril 1936, Madrid, Esfera de los Libros, 2011, p. 144.

16 El Debate, 15-12-1935, editorial. 
pues lo visto en los mítines durante el fin de semana anterior apuntaba en una dirección bien distinta: la comunión de programas en las derechas era casi una entelequia.

Ese fin de semana Calvo Sotelo había dicho que la revolución triunfaba en las alturas (se refería al Presidente de la República) porque se había impedido que la CEDA formara gobierno y se había permitido la vuelta a la legalidad de las organizaciones marxistas. En lo primero coincidía, más o menos, con los cedistas. Pero no era así en aspectos más importantes de cara a una alianza electoral y un programa conjunto de gobierno. El líder monárquico no ahorraba críticas a la CEDA, como venía haciendo durante todo el segundo bienio. Para él, si bien «todas las derechas esta[ban] de acuerdo en que [la República] no ha[bia] implantado las esencias» que ellos personificaban, no podía entender por qué «un sector de ellas s[eguía] en el régimen creyendo que podr[ía] transformarlo desde dentro». Ellos, sentenciaba, «no compart[ían] esa ingenuidad», pues la «República no adoptará nunca formas moderadas». Es decir, los monárquicos no esperaban que los «fundadores» de la República dejaran de considerarla «con sentido patrimonialista». Aunque luego Calvo puntualizara que esa diferencia «no estorba[ba] al frente antirrevolucionario», eso era una cuestión discutible. De hecho, él formulaba unas exigencias que, como bien sabía, planteaban graves problemas a los cedistas: pedía que ese frente lo integraran sólo cedistas, monárquicos e independientes; pero «Nada de partido radical». Y además, confirmaba que ya no era posible hacer campaña para revisar la Constitución; la de 1931 estaba «cancelada» y era necesaria una $\left\langle\right.$ nueva» ${ }^{17}$.

Calvo estaba decidido a tensar la cuerda. Así afrontó su relación con la CEDA y así planteó su estrategia para el pacto electoral. Pero Gil Robles, que durante esos días y hasta mediados de enero también criticó duramente a Alcalá Zamora, dejando incluso que sus juventudes avivaran el fuego y pusieran sobre la mesa reivindicaciones maximalistas, iba a jugar su propia partida. Hay varios aspectos de su discurso en esos días que son muy significativos. Uno, en absoluto menor, es que para él el problema no era tanto una «mala» Constitución como un mal funcionamiento del Parlamento. Su afán no era suprimir la cámara sino disponer de una mayoría que hiciera gobernable el país y permitiera evitar la intromisión del Presidente en el juego parlamentario. Y decía confiar plenamente en las urnas para resolver ese problema, sin descartar además el pacto con todos aquellos que estaban contra la revolución, incluidos los republicanos -que, en definitiva, eran esenciales para lograr una mayoría parlamentaria que facilitara gobiernos estables- $-^{18}$.

Los días posteriores a la Navidad y hasta la primera semana de enero fueron un hervidero de rumores sobre si habría o no acuerdo entre la CEDA y los monárquicos. Calvo siguió presionando a favor del frente derechista tal y como él lo había definido. Pero esa presión pública reflejaba, en verdad, una cierta derrota en el terreno de las conversaciones privadas. De hecho, el mismo 26 de diciembre se producía una entrevista entre Maura y Gil Robles cuyo objetivo era extender el frente conservador, si bien las diferencias entre ambos no eran menores. Parte de la prensa interpretaba que Maura no estaba de acuerdo en la alianza con «algunos radicales» y había vetado la unidad con los monárquicos. Por otro lado, estaba planteado el problema de la coalición con los grupos que habían apoyado al gobierno Portela, a los que Gil Robles, en un primer momento, había excluido de todo acuerdo. A

$17 A B C, 24-12-1935$, editorial y mitin de Calvo en Albacete.

18 Mitin en Cáceres, en $A B C$, 24-12-1935. 
su vez, en esos días se producian otras reuniones, con Gil Robles como protagonista. En una de ellas, con Abilio Calderón, se confirmaba el acuerdo con la derecha independiente ${ }^{19}$.

E1 27, tras una nueva entrevista entre Gil Robles y Calvo Sotelo, todo eran rumores y, pese a la impaciencia monárquica, no se confirmaba el frente antirrevolucionario. Es más, la CEDA seguía jugando su partida, que nada tenía que ver con las pretensiones de Calvo. $\mathrm{Su}$ secretario general, Geminiano Carrascal, la mano derecha de Gil Robles en aquellas semanas de intensa negociación, daba a conocer una nota que dejaba muy claros algunos aspectos, asegurando que en esos mismos términos se iba a pronunciar el

Consejo Nacional convocado para el día 30. La CEDA salía al paso de los rumores asegurando que eran partidarios de «un amplísimo frente contrarrevolucionario» que se amoldara « a las particularidades electorales de cada provincia». Ese frente-por el momentoera incompatible con el «pretendido partido de centro que quiere improvisar el Sr. Portela» $\mathrm{y}$, por tanto $-\mathrm{y}$ con esto metían presión, entre otros, a los agrarios y los melquiadistas-, con los partidos que «coadyuven desde el Gobierno» a ese propósito. Carrascal aseguraba, además, que, aun yendo sola, la CEDA tenía aseguradas las mayorías en veinte provincias y las minorías en las restantes. Así pues, su advertencia era implícita pero contundente: no cederían a presión alguna incluso a riesgo de que no hubiera frente electoral conservador. La reunión del Consejo Nacional de la CEDA confirmó esos términos, abriendo la puerta a pactos en las provincias con los republicanos que quisieran combatir la revolución. Y para desesperación de los monárquicos, hizo público un comunicado preciso en el que descartaba que el acuerdo electoral fuera acompañado de «un compromiso para programas mínimos» o «un pacto de carácter general para toda España». Es más, rechazaban tajantemente todo aquello «que ligue a la Ceda con los partidos monárquicos una vez terminada la contienda de las elecciones $\rangle^{20}$.

No es extraño que durante las dos primeras semanas de enero los monárquicos estuvieran cada vez más angustiados por algo que no podían reconocer en público pero que era un secreto a voces: la CEDA no se plegaba a sus presiones para una alianza sin los republicanos y no estaba por la labor de pactar nada que supusiera un compromiso postelectoral. Es evidente que ambas cosas habrían supuesto una especie de haraquiri de los posibilistas y una humillación ante las duras críticas que los monárquicos venían dedicándoles desde mucho antes de octubre de 1934.

Significativamente, la prensa monárquica criticaba, un día sí y otro también, que el pacto incluyera a aquellos que como el Partido Agrario «acaban de dar nueva prueba de su versatilidad»; o a los que, como Maura, se asociaba con las trágicas jornadas de anticlericalismo violento de mayo de 1931. Para ellos, además, el pacto debía ser un «compromiso permanente» ${ }^{21}$. Pero a Gil Robles esa presión parecía importarle poco, sumergido como estaba en negociaciones a varias bandas y empeñado en el compromiso con sus antiguos socios de gobierno, los radicales. Poco antes de Reyes, tras una larga conversación entre Gil Robles y Lerroux, el Comité Nacional del Partido Radical ratificaba el acuerdo de «ir a la lucha electoral con partidos afines y especialmente con la Ceda». Es más, Gil Robles sabía no sólo que la unidad programática que pedían los monárquicos implicaba una claudicación en toda regla, sino que distintos sectores de la CEDA no veían con buenos ojos la unidad con aquéllos. Y no eran sólo los próximos a Luis Lucia o Giménez

19 ABC, 27-12-1935; Ahora, 28-12-1935; El Heraldo de Madrid, 27 y 28-12-1935; y La Voz, 26-12-1935.

20 ABC, 28-12-35; El Heraldo de Madrid, 31-12-1935; y La Vanguardia, 1-1-1936.

$21 A B C, 1-1-1936$. Véase también editoriales de los días 9, 12 y 16 de enero. Y La Nación, 5-1-1936, este último citado en Bullón de Mendoza, José Calvo..., p. 554. 
Fernández. El sevillano Jesús Pabón atacó por escrito a la minoría de Renovación Española. Y era lógico que así fuese cuando durante muchos meses esa minoría, y especialmente los amigos de Calvo Sotelo, habían hecho todo lo posible para impedir que la coalición radicalcedista siguiera en pie. Además, pese a su propio lenguaje antimarxista, muchos cedistas no podían compartir los exabruptos que se oían en las filas monárquicas, como cuando el día de Reyes el marqués de la Eliseda insistió en que las «formas no son accidentales» y que era «más fácil restaurar la Monarquía que cambiar la República» ${ }^{22}$.

Por el contrario, el discurso electoral cedista, aun siendo muy beligerante contra el Presidente de la República, en lo demás se mantuvo dentro de los límites del posibilismo de forma si cabe más clara que en 1933; ningún cedista pidió, de forma autorizada, la destrucción de la República ${ }^{23}$. Y a diferencia de alfonsinos y carlistas, la participación democrática era considerada como el mejor cortafuego de la revolución, en tanto en cuanto permitiese un parlamento conservador gobernable. En un polémico discurso dado en Vigo a comienzos de enero, Gil Robles atacó duramente a Alcalá Zamora, pronunciando unas palabras que fueron censuradas, aunque se publicaron días más tarde, una vez restablecidas las garantías. Dijo que no era demagogo «el jefe de un partido que denuncia las infracciones de la Constitución» sino el «el jefe del Estado que la infringe» y «el Gobierno que sanciona extralegalmente la actuación del jefe del Estado.» Pero también repitió algo que marcaba una distancia capital -no una mera diferencia táctica- con los monárquicos:

Yo tengo respeto a los hombres que profesan noblemente una ideología, aunque ésta sea distinta a la mía. A mí no me importa que en este lugar haya quien no comulgue con mis ideas. Si hay alguien, yo trataré de convencerle, utilizando los medios de persuasión, pero si no lo consiguiera, continuaría guardándole mis respetos. Con unos o con otros. Claramente. Pero a votar como ciudadanos ${ }^{24}$.

Es verdad que en esos días las Juventudes de AP fueron más allá en sus ataques a los socialistas y sus exigencias de cambio constitucional. Pero no lo es menos que en el ecuador de la campaña Gil Robles limitó la libertad de sus jóvenes, suspendiendo alguna de sus publicaciones y exigiendo que en los mítines no se salieran del guión establecido por la dirección del partido en Madrid ${ }^{25}$. Lo hizo no sólo porque le disgustaran ciertas concomitancias con los monárquicos, sino porque a nadie se le ocultaba que ese discurso dificultaba su relación con los partidos republicanos.

Para desesperación de algunos, todavía a primeros de la segunda semana de enero continuaba el ir y venir de rumores sobre el acuerdo de las derechas. El día 8 Gil Robles filtraba de nuevo su actitud firme de «no establecer un comité de enlace, como se hizo en las elecciones de 1933». El Sol aseguraba en ese momento que los «trabajos electorales» en las derechas eran intensos. Al parecer, la Ceda lucharía «unida a los monárquicos sólo en cinco provincias», aquellas como Madrid o Santander donde «los partidos de centro derecha no

22 Mitin monárquico en Antequera. En $A B C, 7-1-1936$. Gil Robles, No fue posible ..., p. 406.

23 La campaña cedista en las elecciones de 1933, en R. Villa Garcia, La República en las urnas. El despertar de la democracia en España, Marcial Pons, Madrid, 2011, p. 251-267.

$24 A B C, 7$ y 9-1-1936; El Sol, 7-1-1936.

25 Richard A.H. Robinson, Los origenes de la España de Franco. Derecha, República Revolución, 1931 1936, Barcelona, Grijalbo, 1973, p. 351. Siempre se citan artículos del boletín de las JAP para hablar del extremismo de las juventudes. Pero junto con eso también hay que recordar que los numerosos discursos dados por japistas en la campaña electoral de 1936 no fueron sustantivamente diferentes a los de sus mayores. Un ejemplo muy significativo de esa disciplina son los discursos de presentación de candidatos de la JAP en Madrid, en El Debate, 7-2-1936 y ABC, 8-2-1936. 
tienen fuerza.» Pero en el resto iría «unida a los mauristas, agrarios, etc». También se abría paso cada vez de forma más clara el acuerdo en Cataluña con la Lliga.

Esa información parecía confirmar que, tras nuevos contactos entre Gil Robles y Maura por un lado, y Gil Robles y Calvo Sotelo por otro, el líder cedista no cedía ante ninguno de sus interlocutores, si bien concordaba con Maura y otros republicanos en que no habría pacto postelectoral alguno con los monárquicos. De hecho, las relaciones entre Gil Robles y el líder monárquico pasaban por su peor momento, hasta el punto de que algunos periódicos aseguraban el día 10 que el último encuentro entre ambos «se [había] interrumpi[do] bruscamente». La «discrepancia fundamental» que había provocado «una discusión enconada» residía, claro está, en la negativa cedista a pactar «un programa mínimo de actuación para desarrollar en la Cámara futura $\gg^{26}$. Así pues, todavía a mediados de enero la CEDA mantenía dos ideas inamovibles: ni bloque monárquico-cedista ni acuerdo con los portelistas. «Ya he dado órdenes concretas y definitivas a todas las agrupaciones de provincias», declaraba Gil Robles con toda la intención, «de que no iremos a la lucha electoral en unión de ninguno de los candidatos que representan al Gobierno». Un día más tarde, El Debate, fiel vocero de la línea de acción gilroblista, respondía a la ansiedad de la prensa monárquica: el frente electoral se formará poco a poco, «sin compromisos que desdibujen la peculiar significación de cada grupo y su libertad de acción.» ${ }^{27}$.

Esa era la situación cuando el domingo 12 de enero Calvo Sotelo pronunció unas palabras en un mitin que supusieron un importante punto de inflexión. Como de costumbre, el extremismo y la soberbia del líder monárquico exasperó a Gil Robles. Tres aspectos debieron de acabar con su paciencia: el primero, cuando Calvo dijo que el segundo bienio «de tregua» ha mostrado «lo más que la República puede ofrecer a la derecha»; es decir, que los accidentalistas se equivocaban confiando en cambios dentro del sistema. El segundo, cuando reiteró que deseaban la unión de derechas pero exigió - como si él liderara el grupo más importante y nutrido de las derechas y pudiera poner condiciones- que el pacto incluyese el compromiso de declarar constituyentes las próximas Cortes, que deberían «sustituir totalmente la Constitución». Y el tercero, en una línea de populismo autoritario, cuando afirmó que frente a la violencia que es «palanca del socialismo», «la sociedad» necesita «apelar también a la fuerza» para una «defensa eficaz»; luego, un «Estado fuerte» requiere de un «ejército poderoso» ${ }^{28}$.

Nada de todo esto casaba con el discurso del líder cedista. Es significativo que ese mismo día, en Córdoba, Gil Robles no dudase en contestar a una parte del público que pronunció palabras contra el régimen justo en el momento en el que él estaba criticando el comportamiento de Alcalá Zamora.

Seamos demócratas, [dijo] enjuiciando bien sobre la democracia. Y no se nos diga que esto es atacar al régimen [...] Se puede atacar al presidente de la República y salvar la Presidencia de la República en el ataque. Eso es lo lógico, lo democrático, lo republicano y lo legal. Porque los vicios de un hombre no pueden confundirse con los errores de un sistema. (Gran ovación).

Y añadió algo que bien puede interpretarse como una respuesta a las continuas apelaciones de Calvo Sotelo: «El ejército es un instrumento nacional al servicio de la Patria, y no ha de estar, ni puede estar, ni debe estar, a la orden de ningún partido» ${ }^{29}$.

26 La Vanguardia, 9 y 10-1-1936. El Sol, 9-1-1936.

27 El Debate, 11-1-36 y Ahora, 11-1-1936.

28 ABC, 14-1-1936 y Ahora, 14-1-1936.

29 Ibidem. 
Pese a la presión monárquica, Gil Robles volvía a la carga en público y el día 13 advertía:

Francamente. Creo que habrá unión contrarrevolucionaria... Ahora, sí no la hubiera la Ceda no sería la que más perdería, porque creo que para sacar las minorías en toda España, no tendríamos que hacer un gran esfuerzo. En este caso tendríamos seguros, como punto de partida, ciento diecinueve diputados [...] De modo que si a alguien le interesa que haya unión, debe ser a los otros partidos. Ellos verán si quieren luchar solos contra los socialistas y disputarles las mayorías. Sí vamos unidos, las tendremos en toda España. Si no, yo me llevo las minorías, y ellos verán lo que hacen.

Nada podía exasperar más a quienes estaban a su derecha que el hecho de que la CEDA insistiera en no acordar un pacto para terminar con la República después de las elecciones, recalcando además que seguiría negociando con los republicanos. Es evidente que, por otro lado, esas tensiones reflejaban un desacuerdo en cuanto al reparto de puestos en las listas electorales. Por eso los cedistas no sólo no cedían sino que amenazaban. Y los monárquicos ponían el grito en el cielo: la CEDA se

cree la dueña absoluta del país y en condiciones de imponer exigencias [...] Lo que se pretende es mermar, reducir hasta lo inverosímil, la representación monárquica, y con eso, naturalmente, no podemos estar de acuerdo los que hemos sacrificado toda la vida a una convicción, mucho menos aún, a sabiendas de que nuestro sacrificio sólo ha de servir para acrecentar las posibilidades de consolidación de la República, como ha ocurrido en los dos últimos años ${ }^{30}$.

Así pues, en un momento muy delicado de las relaciones entre cedistas y monárquicos, la segunda quincena de enero resultó decisiva para facilitar un acuerdo que, finalmente, respondió básicamente a los planteamientos de los primeros. Fue posible porque entre el 16 y el 24 se sucedieron tres hechos importantes. El primero y más tangencial es que Gil Robles cortó en seco toda posible insubordinación en los japistas, facilitando así la relación con sus aliados republicanos y las demandas de los sectores socialcristianos de su propio partido. Por otra parte, ya no le interesaban las críticas exacerbadas contra don Niceto. E1 día 18 ordenaba la retirada del número más reciente del semanario J.A.P. ${ }^{31}$. Lo segundo es que, para colmo de los monárquicos, la CEDA se estaba acercando a los portelistas, de tal forma que no sólo no habría bloque de derechas antirrepublicanas sino que Gil Robles aceptaba alguna lista conjunta con candidatos del gobierno allí donde la lucha triangular resultaba muy peligrosa ${ }^{32}$. Y el tercer aspecto, en absoluto menor, fue la ruptura entre Gil Robles y Calvo Sotelo, harto el primero tanto de las salidas de tono de su interlocutor como de sus pretensiones de hegemonizar las derechas. De hecho, si entre el 19 y el 23 se lograba por fin aclarar las condiciones del acuerdo con los monárquicos, esto ocurría tras la sustitución de Calvo Sotelo por Goicoechea en las negociaciones ${ }^{33}$.

Pero para llegar a ese acuerdo hubo primero que salvar el obstáculo principal, que no era solamente una cuestión de reparto de puestos: los monárquicos querían un acuerdo de programa, mientras que los republicanos radicales y conservadores presionaban a Gil

30 La Nación, 14-1-1936.

$31 A B C, 19-1-1936$ y El Sol, 19-1-1936.

32 Cuanto menos desde el día 17 de enero había conversaciones que apuntaban a un posible acuerdo parcial entre candidatos cedistas y gubernamentales. Ahora, 18-1-1936.

33 «E1 señor Goicoechea sucede al señor Calvo Sotelo en la representación de los monárquicos»; Ahora, 23-1-1936. «E1 señor Gil Robles», concluía la nota política de La Vanguardia, "ha roto todo trato político con el señor Calvo Sotelo. El suceso ha caído, naturalmente, como una bomba en el campo de las derechas. [...] La ligereza, o la indiscreción, o quizá la franqueza -que todo puede ser- del señor Calvo Sotelo, lo ha precipitado». La Vanguardia, 23-1-1936. 
Robles en sentido contrario. Aceptaban estos últimos, después de muchas negociaciones, que hubiera listas en las que la CEDA pactara con los monárquicos, pero no cedían en ningún tipo de pretensión que pudiera ser interpretada como una victoria del afán monárquico por convertir las próximas Cortes en el inicio de un período constituyente y el principio del fin de la República. Hubo un momento, entre el 20 y el 22, en el que la negociación estuvo a punto de naufragar. De hecho, el titular de $\mathrm{ABC}$ el día 21 era totalmente engañoso: «Ayer se concertó entre los jefes de la fuerzas de derechas la unión contrarrevolucionaria» ${ }^{34}$. Se refería a un posible acuerdo cerrado por Gil Robles con los monárquicos la tarde del 20 y que, al día siguiente, Calvo Sotelo presentaría en público, en un discurso pronunciado en Cáceres, como algo cerrado ${ }^{35}$. Miguel Maura, muy inquieto por esos rumores y por las exigencias monárquicas, visitó a Gil Robles, seguramente para escuchar de su boca que la Ceda no respaldaba todas las peticiones de los monárquicos para el día después de las elecciones. Más tarde, tras una reunión conjunta entre Alba, Maura, Cid y el líder cedista, los tres primeros publicaron una nota la noche del lunes 20. Reconocían haber reiterado a Gil Robles su apoyo a «las candidaturas de centro y derecha coaligadas» pero «sintiendo, ante todo, una preocupación legítima por las instituciones republicanas y por la vida fecunda de las próximas Cortes». Le habían pedido, así, que con la confección de candidaturas «no se p[usiera] en riesgo el normal cumplimiento de aquellos dos postulados esenciales: Defensa de la República y función útil del Parlamento.» ${ }^{36}$.

A la presión por la izquierda se sumó la del propio partido de Gil Robles. Al parecer, el día 22 Luis Lucia le pidió que no firmara ningún pacto con los monárquicos; según algunos medios, llegó incluso a amenazar con la escisión. De cualquier forma, el líder de la Derecha Regional Valenciana reconoció ante la prensa su «asombro» ante las manifestaciones hechas por Calvo Sotelo en Cáceres -en las que éste anunció un pacto programático con la CEDA que incluía las exigencias maximalistas de los monárquicos- y tuvo palabras contundentes en cuanto a la naturaleza de la CEDA: «se es un grupo gubernamental o no se es. El que no lo sea puede decir lo que le dé la gana; pero el que sea gubernamental tiene que atenerse a los medios legales para conseguir sus fines». Además, dijo estar autorizado por Gil Robles para desmentir rotundamente que las palabras de Calvo Sotelo contaran con el beneplácito de aquél. Se habría podido firmar un manifiesto electoral con las derechas, reconoció, pero ahora, tras las palabras de Calvo, quedaba descartado ${ }^{37}$.

34 En declaraciones a la prensa, Gil Robles desmentia esa información y aseguraba que de momento no había manifiesto conjunto de las derechas; desmentía además que a los monárquicos se les fueran a dar 75 puestos. El Sol, 21-1-1936.

35 En esa reunión del 20 habrían estado Gil Robles, Goicoechea, Calvo Sotelo y -aunque no con seguridad-Martínez de Velasco. Los dos últimos «sometieron a la aprobación» cuatro puntos: «las próximas Cortes, al constituirse, se declararán Constituyentes; inmediata destitución del Presidente de la República; constitución de un gobierno provisional, y sustitución del Sr. Alcalá Zamora en la jefatura del Estado por un general». Según El Sol, el «primer punto fue aprobado por unanimidad; los dos segundos, rechazados por el Sr. Gil Robles». El Sol, 22-1-1936. En sus memorias Gil Robles confirma que habría aceptado el primero, pero discrepando «de la formulación y el planteamiento». No fue posible..., p. 410. El ejemplar de Ahora (22-1) dice, sin embargo, que Gil Robles habría llegado a un «completo acuerdo» con los monárquicos, incluido el manifiesto. Pero Martínez de Velasco, en El Heraldo de Madrid (22-1) desmintió que se hubiera pactado nada de lo que se rumoreaba.

36 Ahora, 21-1-1936; El Sol, 21-1-1936; La Vanguardia, 21-1-1936; El Heraldo de Madrid, 21-1-1936.

37 El Sol, 22 y 23-1-1936 En la versión de El Heraldo de Madrid, 22 y 23-1-1936, se daba a entender que las palabras de Calvo Sotelo pidiendo unas cortes constituyentes habrían sido fruto de un acuerdo en una reunión previa con Gil Robles en la casa del marqués de la Vega de Anzó. Y también se indicaba que una gestión de Lucia con Maura había sido clave para convencer a los republicanos de que la CEDA no cederia a las pretensiones monárquicas. En su Memorias, Gil Robles califica estas versiones 
La constitución del frente electoral antirrevolucionario pasó ayer por un momento delicado, aseguraba Ahora en su edición del día 23. Y así había sido. Según algunos, la posibilidad de una coalición monárquico-cedista se había evitado gracias a la amenaza de los partidos republicanos de acercarse al Gobierno y pactar con Portela ${ }^{38}$. Pero lo cierto era, primero, que los planteamientos hechos públicos por Calvo Sotelo no respondían a un pacto previo con Gil Robles que significara la firma de un acuerdo postelectoral y la demanda expresa de la reforma «total» de la Constitución, aunque parece que el líder cedista sí podría haber aceptado, como dijo Lucia, algún tipo de manifiesto conjunto, aunque redactado por los cedistas y los radicales ${ }^{39}$. Por otra parte, las exigencias de número de puestos en las candidaturas que llegaron a realizar los monárquicos, de hasta 68 , eran a todas luces inasumibles para los cedistas y no se correspondían con la escasa presencia y organización de Renovación Española en muchas provincias.

No ya la prensa cercana a la CEDA, como El Debate o $Y a$, sino otros medios de alcance nacional interpretaron que, una vez desplazado Calvo Sotelo y descartado cualquier acuerdo programático con los monárquicos, Gil Robles había dado un paso más en el sentido de robustecer la opción legalista. $\mathrm{El} \mathrm{Sol}$, un medio en absoluto sospechoso de antirrepublicanismo, venía asegurando desde días antes que Gil Robles «está resuelto a gobernar con la República y no quiere que nada estorbe esta aspiración de su partido.» Y La Vanguardia del día 23 consideraba «innegable que con su actitud de hoy el señor Gil Robles fortalece su posición política dentro de la República» ${ }^{40}$.

Lo cierto es que después de esas tensas jornadas, Alba, que era la voz cantante de los radicales en la negociación electoral con la CEDA, podía declarar que estaba satisfecho con las explicaciones y la actuación de Gil Robles.

El pacto está desde hoy más firme, y a él vamos con más entusiasmo que nunca [...] El señor Gil Robles ha aceptado las reflexiones que hacíamos en nuestra nota para procurar a todo trance la consolidación de la República y que el nuevo Parlamento realice una labor útil para la República.

Y Maura, siempre dado a un cierto sensacionalismo, aseguraba:

Yo, que asistía a esta reunión como republicano [...] he salido satisfecho y más entusiasta del bloque electoral que nunca. He visto en el señor Gil Robles [...] un gran sentido de cordialidad, y sobre todo, un marcado espíritu liberal. Estoy, por tanto, sumamente satisfecho, pues se ha reconocido por todos que hay que impedir a todo trance que se malogre esta coalición y hay que alcanzar la mayoría republicana de centro-derecha que sea instrumento de Gobierno después del triunfo electoral ${ }^{41}$.

de «falsedades» de los «periódicos de izquierdas» y señala que las gestiones y declaraciones de Lucia se hicieron con su conformidad y dirección previa. No fue posible ..., p. 411. Javier Tusell, sin embargo, hizo una interpretación contraria a lo sostenido por Gil Robles; un comentario crítico sobre esto puede verse al final de este artículo.

38 «Nota política» de La Vanguardia, 23-1-1936.

39 Ahora, 23-1-1936, que da por seguro que se «había aprobado [...] la redacción de un manifiesto electoral en la pasada reunión del señor Gil Robles con los representantes monárquicos; documento al que no concedía el jefe de la CEDA la trascendencia que le han atribuido los partidos republicanos». En declaraciones recogidas por El Debate, 23-1-1936, Calvo aseguraba haber hablado de manifiesto porque «el lunes pasado se acordó que a la noche siguiente se reunirían los señores Goicoechea y Gil Robles para firmar[lo]».

40 El Sol, 19-1-1936. «Nota política) de La Vanguardia, 23-1-1936.

41 Ahora, 23-1-1936. El Heraldo de Madrid, 23-1-1936. 
Ciertamente, en esto último residía uno de los puntos clave. La CEDA mantendría sus conversaciones con los monárquicos, pues lo contrario podía suponer perder escaños en algunas provincias. Pero no aceptaba las peticiones de los monárquicos de involucrarse en un pacto postelectoral con ellos. Y esta era una cuestión central, pues significaba que el partido de Gil Robles, al que muchos medios, a diestra y siniestra, auguraban el grupo mayoritario en las próximas Cortes, rechazaba hacer campaña contra la República y postular la revisión total de la Constitución. Para la CEDA lo fundamental era orientar las alianzas y el discurso de tal forma que se pudiera conseguir después de las elecciones una mayoría de gobierno que incluyera al centro-derecha republicano y que hiciera, ante todo, gobernable el parlamento.

De ahí que a partir de ese momento y hasta el 16 de febrero, además de moderar algo sus ataques a Alcalá Zamora, Gil Robles no dejara de insistir en que la «alianza contrarrevolucionaria» era algo «amplísimo» que empezaba allí donde «acaba[ba]n los contubernios revolucionarios». Como aseguró en un importante y multitudinario mitin en Toledo, celebrado poco después de la ruptura con Calvo Sotelo, si él estaba dispuesto a pactar con los monárquicos, pese a los «extremos» que aquellos habían usado contra los cedistas, por qué no iba a pactar con el centro y la derecha republicanos, que sin embargo habían sido sus aliados de gobierno. Dicho con el lenguaje apocalíptico y frentista del momento: «Yo no pregunto a nadie de dónde viene cuando viene a luchar por España y por nuestra civilización». Por lo tanto, la gente del Bloque Nacional debía tener algo claro, a juzgar por la cantidad de veces que lo repetían los cedistas en sus mítines: «Nosotros mantenemos nuestra posición y nuestra táctica, porque entendemos que hay que mirar no al momento inmediato, sino a un momento un poco más lejano» ${ }^{42}$.

Pero no sólo era eso. También se trataba, como advirtió El Debate tras ese importante mitin de Gil Robles, de establecer una línea divisoria con su extrema derecha. Y para eso había que reiterar que no se luchaba en las urnas contra la legalidad sino en su defensa. «La victoria de los comicios, que será plenamente legal, que en modo alguno puede significar un átomo de de imposición y de violencia, nada valdría si no la consolidaran en sus efectos las mismas vías de la legalidad. $\gg^{43}$. Y esta no era una cuestión baladí, pues Calvo Sotelo y otros monárquicos andaban haciendo una campaña en la que se justificaba el derecho de rebeldía de los católicos contra el régimen en la medida en que consideraban conculcada la legalidad. Ellos, como volvió a repetir Calvo Sotelo en esos días, tenían claro que: «La República será (siempre) lo que es ahora: un pretexto para la revolución $\rangle^{44}$.

Es decir, que los monárquicos, como reconocía La Nación tras el jarro de agua fría que había supuesto la ratificación del acuerdo cedista-republicano, si bien admitían -con resignación evidente- que «en las circunstancias actuales es necesario llegar a inteligencias con los menos peligrosos», querían -en directa alusión a los cedistas- «proclamar también a voces que no se puede ser monárquico de corazón y republicano de conducta, sino que todos los que se llamen republicanos no son nuestros afines, y que todos los que piensen en monárquico y actúan en republicano $[\ldots]$ ocasionan también un enorme estrago al interés supremo de la Patria ${ }^{45}$.

Pero la presión no hizo mella en el cedismo. Es más, según se entró en la primera semana de febrero Gil Robles decidió, finalmente, desdecirse de sus propias palabras y aceptar

42 Todo del mitin en Toledo, en $A B C, 24-1-1936$, p. 17-21.

43 El Debate, 24-1-1936.

44 Ahora, 24-1-1936 y La Vanguardia, 23-1-1936.

45 La Nación, 4-2-1936. 
acuerdos puntuales en algunas provincias con candidatos portelistas. Entre el 6 y el 9 de febrero concedió dos o tres entrevistas importantes en las que ratificó su idea de alianzas «variadísimas». Lo fundamental no era el dilema monarquía o república sino «derrotar en las urnas a las izquierdas». Y hacerlo dejando claro que

esas alianzas no prejuzgan nuestra actitud en orden a los problemas de la política futura. ella iremos cada uno de nosotros con nuestro programa, nuestra táctica y nuestro criterio [...] De igual modo que nosotros no hipotecamos nuestro criterio, no queremos tampoco que lo hipotequen los demás ${ }^{46}$.

Con el típico pragmatismo y esa ambigüedad calculada que había caracterizado buena parte de su trayectoria anterior, Gil Robles marcaba distancias con unos monárquicos cada vez más enojados, no ya por los acuerdos con los republicanos sino por el empeño de la CEDA en no variar sus objetivos postelectorales. El líder cedista reconocía, y esto abiertamente, que no le preocupaba tanto la reforma de la Constitución como impedir que las futuras Cortes fueran ingobernables: «España no puede aguantar por más tiempo unas Cortes estériles». Por lo tanto, lo fundamental era, entonces, que el gobierno no se empeñara en promocionar candidatos que dificultaran la formación de una mayoría de centro-derecha después de las elecciones. Lo de la Constitución estaba bien, incluso, como le dijo a un periodista de $\mathrm{El} \mathrm{Sol}$, era «esencial». Pero antes de eso había que lograr un «estado espiritual de España, cuya preparación puede exigir medidas legislativas y de gobierno» que sólo podían llegar a través de la victoria electoral y el control de la cámara ${ }^{47}$.

La CEDA reafirmaba así su posibilismo, pero también su empeño en lograr el gobierno por vías diferentes a las que reclamaban los partidos situados a su extrema derecha. Ya en la última semana de campaña, para desesperación de los monárquicos, Gil Robles insistía en que:

Acción Popular no necesita ningún complot por dos razones: primera porque es su norma, su ideología y su táctica no salirse de la ley, y segunda, porque remedando una frase de un hombre ilustre podemos decir: he ahí nuestros poderes señalando al pueblo. No el ejército; es el cumplimiento del deber lo que nos basta para acudir al pueblo y darle una papeleta de votación para que con ella nos de la ratificación de su confianza.

Para él se trataba de una cuestión evidente: cómo tener «más diputados» y lograr «la ratificación moral que significa la confianza del pueblo». Con ambas cosas, un Gil Robles pragmático aseguraba que la CEDA se presentaría «a los más altos poderes» y pediría «el Poder en nombre de España» ${ }^{48}$.

Para el conjunto de las derechas, y los cedistas no eran menos, aquella consulta electoral era vista como «la batalla definitiva a la revolución». Lo que se iba a «ventilar» era «si España [iba] a vivir un período revolucionario permanente, o si vencida totalmente y para siempre la subversión, podr[ía] comenzar una época de auténtica construcción nacional $\gg^{49}$. Y si de lucha para salvar a España se trataba, no resulta extraño que también el lenguaje de campaña de los cedistas, pese a las diferencias evidentes que los separaban de la derecha monárquica, alcanzara límites difícilmente soportables en un sistema de pluralismo democrático. Es conocido que la CEDA no era una excepción en cuanto al peso del

46 Declaraciones de Gil Robles al diario Ya (6-2) transcritas por Ahora, 6-2-1936.

47 El Sol, 9-2-1936.

48 Mitin de Gil Robles en Sevilla, El Debate, 12-2-1936.

49 Entrevista a Gil Robles, en Ahora, 6-2-1936 y El Debate, 6-2-1936. 
tradicionalismo católico y antiliberal que campaba a sus anchas por las derechas españolas de los treinta. Además, Gil Robles inició la campaña profundamente disgustado con el modo en que se había cerrado la anterior legislatura; la experiencia de la últimas Cortes le había ratificado en que el parlamentarismo, si no iba acompañado de mayorías estables, imposibilitaba el gobierno del país. Por eso, dentro de la tónica general del lenguaje antimarxista, llegó a hablar de «aplastar» a los adversarios que defendieran ideas «ilícitas», como las de la lucha de clases ${ }^{50}$. También los cedistas, a veces, calificaron a sus adversarios de «traidores», «renegados», o «aliados de pistoleros», como señaló Tusell ${ }^{51}$. Con todo, aunque el discurso cedista se viera contagiado por la dura controversia que mantenían los oradores de derechas con sus rivales del Frente Popular, es una burda simplificación quedarse en ese nivel para el análisis; por no hablar de lo poco honesto que resulta citar sólo fragmentos de los discursos de Gil Robles - como el mencionado más arriba en el que usó el término «aplastar»- previa manipulación y recorte.

En 1936 no hubo, a diferencia de 1933, una coalición nacional con los monárquicos, pese a que estos la pidieron a gritos durante la segunda quincena de diciembre. Como ya señalara Tusell, no hubo ningún comité coordinador de una candidatura única de derechas. De hecho, la CEDA acordó alianzas electorales muy variadas, que incluyeron finalmente a distintos republicanos radicales, conservadores, independientes y agrarios. No se pactó un programa con los monárquicos no ya porque eso hubiera impedido el acuerdo con los republicanos, sino también porque las exigencias de los primeros pasaban por abandonar el posibilismo. En la línea abierta por Tusell, se ha venido sosteniendo que si Gil Robles no aceptó el acuerdo programático propuesto por Calvo Sotelo no fue porque él y una parte de la CEDA no estuvieran de acuerdo en, por ejemplo, la revisión de la Constitución y la destitución de Alcalá Zamora, sino porque el sector de Lucia y Giménez Fernández amenazó con romper la disciplina,

Es casi seguro que el líder de la DRV mostró a Gil Robles su desacuerdo con un pacto de esas características, pero también lo es que la evolución de las conversaciones privadas y el discurso público sostenido por la cúpula gilroblista desde finales de diciembre indican que era una pura fantasía monárquica esperar que la CEDA firmara un acuerdo con ellos que implicase el reconocimiento público de la defunción del posibilismo y nada menos que la formación de un «gobierno provisional» con un general, posiblemente Sanjurjo, presidiendo el régimen. Y es inverosímil sostener, además, que sólo por la intervención de Lucia la CEDA no terminó en manos de los monárquicos. Como dijo Tusell, podía haber acuerdo entre Gil Robles y Calvo Sotelo en promover la destitución del Presidente; ahora bien, eso, a diferencia de lo que señaló este mismo autor, no era una declaración de antirrepublicanismo sino una medida que se podía promover dentro de las previsiones de la propia Constitución.

Un detenido análisis de todas las fuentes periodísticas disponibles, y no sólo de las memorias de algunos protagonistas, apunta a que Gil Robles no se apartó sustancialmente de la verdad en sus Memorias cuando dijo que había varios puntos del programa propuesto por los monárquicos que eran inasumibles para la CEDA, con independencia de la presión o no de su sector socialcristiano. Y eso tanto porque era necesario pactar con los republicanos y algunos portelistas para tener buenos resultados, como porque, tal y como se ha mostrado en este artículo, Gil Robles mantuvo un criterio pragmático, pero más o menos

50 Mitin del 9 de febrero, en El Debate, 11-2-1936 y Ahora, 11-2-1936.

51 Tusell, Historia de la..., vol. I, p. 216. 
coherente, durante todas esas semanas, un criterio que suponía una diferencia sustantiva con los monárquicos y una firme defensa de los postulados posibilistas. En ese sentido, por tanto, no parece haber razones bien fundadas para sostener tajantemente la idea de que Gil Robles mantuvo inicialmente una posición «dubitativa» ante las propuestas de Calvo Sotelo y sólo la presión de Lucia y los republicanos conservadores «hizo que el plan acabara abortando $\gg^{52}$.

La campaña del Bloque Nacional no fue solamente antimarxista, sino «antirrepublicana y antidemocrática $~^{53}$. Mientras que la CEDA, a pesar del radicalismo inicial de sus juventudes y los famosos gritos de «iJefe!, ¡Jefe!», concentró su discurso en, primero, atacar al Presidente de la República en términos que pudieron resultar groseros y, segundo, el miedo a la revolución; además, buena parte de sus mítines se dedicaron a defender la gestión realizada en el segundo bienio, sin arrepentirse, sino todo lo contrario, de la colaboración con los republicanos radicales. Las diferencias de fondo entre el discurso cedista y el monárquico fueron más que notables, tanto en las palabras de los líderes nacionales como en el ámbito de las campañas locales ${ }^{54}$. No es que algunos cedistas no compartieran aspectos doctrinales con los monárquicos y un mismo afán antimarxista; también ellos estaban fuertemente mediatizados por el miedo a que los protagonistas de Octubre recuperaran el poder y cumplieran con las promesas que hacían en campaña. Y lo que sí hubo en la campaña cedista, una vez que las alianzas se fragmentaron y hubo que convivir con compañeros tan diferentes, fue una cierta inconcreción de las propuestas para el día después de las elecciones -algo, por lo demás, propio de un catch-all party como ya era la derecha gilroblista-. En cualquier caso, como revela el devenir de las negociaciones que se han relatado más arriba, hubo algo más que una diferencia táctica entre la CEDA y los partidos antirrepublicanos de la derecha radical. Ni siquiera el hecho de que la CEDA hubiera sufrido la muerte de no menos de dos decenas de japistas en los años previos y que durante la campaña recogiera no menos de cuatro muertos y siete heridos graves más, además de ver cómo la mitad de todos los mítines reventados en esos días eran suyos, llevó a Gil Robles a posiciones parecidas, en cuanto a la apología de la violencia, a las de otros líderes políticos de la derecha monárquica o la izquierda revolucionaria ${ }^{55}$. Y ésta no es, obviamente, una cuestión menor.

52 G⿺ Robles, No fue posible ..., p. 410-411. Dubitativo, en J. Tusell, Las elecciones del Frente Popular, Madrid, Cuadernos para el Diálogo, vol. I, p. 193. La versión de Vicente Comes, biógrafo de Lucia, en un libro por lo demás notable, está basada en el relato de la prensa de izquierdas, tanto La Voz como El Heraldo de Madrid; por lo tanto, en la línea de Tusell, muy crítica con lo señalado por Gil Robles en sus memorias y haciendo de Lucia un personaje decisivo para centrar a la CEDA. En el filo de la navaja. Biografia politica de Luis Lucia Lucia (1888-1943), Madrid, Biblioteca Nueva, 2002, p. 329.

53 Robinson, Los origenes..., p. 411.

54 Las diferencias entre la campaña de la derecha monárquica y la de los cedistas son también significativas en el ámbito regional. Véase J.M. MaCarro, Socialismo, República y revolución en Andalucia (19311936), Universidad de Sevilla, 2000, p. 396-397; J. SANz Hoya, De la Restauración a la reacción. Las derechas frente a la Segunda República (Cantabria, 1931-1936), Universidad de Cantabria, Santander, 2006, p. 239; TuseLl, Las elecciones..., vol. I, p. 226-277.

55 Datos de violencia electoral, en M. Álvarez TARDí, «The Impact of Political Violence During the Spanish General Election of 1936m, Journal of Contemporary History, 2012. Las cifra de dos decenas, en S.G. PAyne, El colapso de la República, Madrid, Esfera de los Libros, 2005, p. 271. 